\title{
Estereotipos y roles sociales de los bibliotecarios en el discurso cinematográfico
}

\author{
Luis ITURBE FUENTES \\ Doctorado de Bibliotecología y Estudios de la Información. UNAM \\ iturberp@hotmail.com \\ Elsa M. RAMÍREZ LEYVA \\ Instituto de Investigaciones Bibliotecológicas y de la Información. UNAM \\ eramirez@unam.mx
}

Recibido: Abril 2014

Aceptado: Mayo 2014

\begin{abstract}
Resumen: El tema de la representación cinematográfica de los bibliotecarios ha despertado interés en el campo de la bibliotecología, ya que aporta elementos para su estudio en las áreas de liderazgo, educación bibliotecológica, función social de los bibliotecarios, estudios de género, entre otros. En este artículo se presentan dos miradas sobre los bibliotecarios representados en el cine: una de ellas está relacionada con los estereotipos físicos y sus actitudes psicológicas; la otra es sobre los roles sociales, valores, virtudes, temas de género y también situaciones humorísticas que desempeñan, así como los elementos simbólicos que prevalecen en el imaginario social. Todos estos aspectos se identificaron en las diferentes películas en las que se basa el presente análisis.
\end{abstract}

Palabras clave: bibliotecarios; imagen del bibliotecario; bibliotecario en el cine; el estereotipo; características físicas del bibliotecario; aspectos psicológicos del bibliotecario; función social del bibliotecario

\section{Librarian's Stereotypes and Social Role in the cinematographic discourse}

\begin{abstract}
Reel librarians representation is an issue that has awakened the interest of librarianship field because it provides different elements for leadership and direction studies, librarianship education, librarian's social function, and gender studies, among others. This paper shows two views upon reel librarians representation: the first one is related to physical stereotypes and their psychological attitude; the other one is about librarians social role, values, virtues, gender issues, and humorous situations that they play, as well as symbolic elements which prevail through the social imagery. Each of these characteristics was identified throughout the analysis of different films.
\end{abstract}

Keywords: librarians; librarian image; stereotype; reel librarian; librarian physical characteristics; librarian psychological aspects librarian social function 


\section{INTRODUCCIÓN}

Analizar los estereotipos de los bibliotecarios en el discurso cinematográfico resulta de inestimable utilidad, pues ello permite determinar si la persistencia de ciertas imágenes se justifica debido a que el aspecto de la realidad al que corresponden no ha experimentado cambios o si el imaginario social ha sido rebasado por los hechos. En ese orden de ideas, durante la última década, en el ámbito bibliotecológico ha surgido interés por estudiar la forma en que el bibliotecario es representado en el cine, para determinar los elementos ligados al estereotipo que de él se halla anclado en el imaginario social, en términos de apariencia física, actitudes, personalidad, actividad profesional y función social. Las representaciones sociales, definidas por Jodelet (1984:47) como "una forma de conocimiento social que permite interpretar y pensar nuestra vida cotidiana", se construyen a partir de las experiencias, la información y los modelos de pensamiento transmitidos durante el proceso de socialización y difundidos por los medios de comunicación social. Desde luego, no pocas veces, tales representaciones terminan por convertirse en imágenes o ideas de carácter inmutable aceptadas comúnmente por la sociedad, es decir en estereotipos y generalizaciones que influyen en la cabal interpretación de la realidad, como suele suceder con los estereotipos. En caso del bibliotecario con frecuencia se destacan aspectos que resulta negativos, e incluso llega a la caricaturización, como se aprecia en algunas películas, series televisivas y otros mensajes de diversos medios masivos de comunicación, pero, como señala Paz Yanes (2002: 132), "Las representaciones sobre bibliotecarios y bibliotecas sugieren y obligan, mal que nos pese, a reflexionar sobre nuestro propio trabajo y el entorno en el que nos movemos".

Los bibliotecarios aparecen por primera vez en el espacio cinematográfico en 1912, casi una década después de que el cine hace su arribo en la sociedad. Desde entonces y a la fecha han ocupado la pantalla grande, sean como protagonistas o como actores secundarios y sólo en escenas breves. Los encontramos con mayor frecuencia en la filmografía norteamericana, en menor cantidad en el cine europeo y oriental, y en el latinoamericano es prácticamente inexistente, por ejemplo en México la única película es Más negro que la noche, en la cual una de las protagonistas es bibliotecaria.

En algunos estudios sobre material fílmico en que aparecen bibliotecarios y en el propio análisis de las películas, observamos que los estereotipos que los representan son aprovechados para protagonizar roles en los cuales se exaltan virtudes y valores morales, porque son congruentes con su imagen social, por lo tanto resultan creíbles para los espectadores. Recordemos que, por lo general, las imágenes cinematográficas de personas, objetos, lugares y hechos están compuestas de elementos de la realidad, pero también están dotados de simbología, pues se basan en las representaciones sociales estereotipadas, en cuyos casos ciertos aspectos se exageran o distorsionan para propiciar en el 
espectador determinadas emociones, reflexiones o reacciones. A la vez, se tiene el propósito de reducir el esfuerzo y abreviar el tiempo de mirar, escuchar, entender y darle sentido y significado a la escena. Si pensamos en modalidades de lectura, ciertas películas simplifican los contenidos de las escenas para facilitarle al lector la comprensión, pero en otros casos pueden complicar la escena a tal grado que se requiere un esfuerzo mayor de reflexión e incluso tener información o antecedentes para decodificar y comprender el mensaje.

Por ello, el arte cinematográfico busca estereotipos que conjuntan suposiciones de la gente sobre un objeto, situación o personas construidos en una imagen, misma que es perpetuada en la cultura a través de diversos canales, como los medios masivos de información, en este caso, el cine (Rudolph, 2008: 3). La finalidad de esos medios es tener un impacto en el público, en algunas ocasiones al acercarlo a la realidad, en otras al superarla, así se logra, como señala Gubern (2004: 36) "una concreción ostensiva acerca de las características del sujeto u objeto, lo que permite optimizar los elementos de la narrativa cinematográfica."

En el presente artículo se examinan las representaciones sociales del bibliotecario, en sus dimensiones física, psicológica y social, tal como las manifiesta el discurso cinematográfico. En la primera parte, se revisan las características físicas y los rasgos de personalidad del estereotipo del bibliotecario, como pueden verse en siete filmes abordados por Luis Iturbe en su tesis de grado intitulada. Las representaciones del bibliotecario en el discurso cinematográfico. En la segunda, se analizan otras películas donde se ponen de manifiesto valores y virtudes atribuidos los bibliotecarios, pocas veces estudiados en nuestra disciplina (por lo común atenta a los rasgos físicos) y que son determinantes en los roles en donde las actitudes de honor, honestidad, solidaridad, valentía, ética, sabiduría, entre otras, son esenciales para enfrentar problemas y situaciones sociales en los contextos culturales de las historias filmadas.

\section{CÓMO MIRA EL CINE A LOS BIBLIOTECARIOS}

En torno a la literatura bibliotecológica que aborda los estudios sobre la imagen del bibliotecario y su estereotipo, en su trabajo The Librarian and the Crone: Myth and Reality?, Engle explica que la American Library Association interesada en conocer la percepción de la imagen del bibliotecario en la sociedad norteamericana, publicó de 1985 a 1988 una columna titulada "How they're seeing $u s$ " en American Libraries Review. La respuesta que obtuvo en ese periodo fue una sorprendente variedad de imágenes positivas y negativas. Sin embargo, el estereotipo asoció frecuentemente al bibliotecario con una mujer de edad avanzada, sola, malhumorada, restrictiva, no atractiva, peinada con"chongo" (moño de cabello), anteojos y zapatos cómodos (Engle, 1991: 2).

Por su parte, Marinelli y Baker plantearon que aunque muchos bibliotecarios tienen una buena imagen de lo que son ellos mismos, durante décadas se ha 
perpetuado un estereotipo negativo, y que personas que están dentro y fuera de la profesión creen que esa imagen adversa ha afectado el status profesional y la imagen que tienen de sí. Por su parte, Dupré, en su trabajo The perception of image and status in the library profession, propone: dejar de lado la preocupación respecto al estereotipo de lo físico, ya que esto impacta en la inseguridad y la autopercepción del bibliotecario (Dupré, 2001:2). Y Kneale (2009:7), después de 10 años de realizar encuestas entre bibliotecarios, comenta que el estereotipo ha permanecido durante décadas en el pensamiento de las personas, por lo cual considera que la imagen del bibliotecario impacta directamente en su status profesional de la manera siguiente:

a) Afecta la interacción que tiene el bibliotecario con los usuarios, puesto que difícilmente se puede valorar una profesión o un profesional cuando no se entienden o conocen sus conocimientos y capacidades;

b) Repercute en los salarios del profesional;

c) Afecta la identidad del bibliotecario, ya que a los profesionales se les designa con cualquier otro título, por ejemplo, asistente, consultor de información, especialista en información o especialista de recursos digitales, por eso no tiene representación social y se le puede confundir con un informático, un periodista, etcétera (García, 1999: 20);

d) Las actividades profesionales proyectadas se miran como meras actividades operativas.

Así desde la década de 1990, la imagen estereotipada del bibliotecario se comenzó a estudiar en el cine. Es de subrayar que de los múltiples personajes de la cinematografía, el bibliotecario ha sido representado tanto en filmes desde del cine silente en blanco y negro, como hasta el cine sonoro a color. Por ello, nosotros consideramos que en una imagen cinematográfica asignan a los personajes ciertas características y comportamientos, a partir de la determinada concepción cultural, es decir, una expresión artística extraída de la realidad, con la intención de llevar a los espectadores, las imágenes como representaciones reales.

En cuanto a las características físicas asociadas al estereotipo del bibliotecario, Walker refiere que en una encuesta de principios de los las años noventa, identificó al bibliotecario como una persona tranquila, severa, soltera, aburrida, conservadora y con anteojos (Walker, 1993: 16). Mientras que Tevis y Radford señalan que el estereotipo asigna como atributos a una bibliotecaria de edad indefinida, tímida, seria (no sonríe), usa anteojos, viste blusa de manga larga, abotonada al cuello y peinada con "chongo". Le gustan los libros y el silencio, y está obsesionada por el orden (Tevis, 2005: 189; Radford, 2003: 60).

Dado que el estudio del estereotipo de esta figura ha despertado especial interés en el ámbito bibliotecológico, Tevis afirman que entre la inmensa cantidad de 
personajes que la industria cinematográfica ha creado, el cine se interesó particularmente por personificar al bibliotecario; sin embargo, las características que se le atribuyeron a este personaje al mismo tiempo han perpetuado el estereotipo del bibliotecario, cuya imagen no se modifica en la mayoría de los filmes del siglo XX, sino que fortalece la asociación de estas características del bibliotecario percibidas por los productores que realizan dichos los filmes y por los espectadores que interpretan el mensaje (Tevis, 2005: 189). Entre los estudios de otros países que figuran por su representatividad y análisis están los realizados en España (Paz Yanes, 2002; Pinto, 2008) y México (Ramírez, 2007).

Los estudios sobre el personaje del bibliotecario en el cine, en su mayoría son de carácter descriptivo y se concentran principalmente en atributos físicos negativos, ciertos rasgos de personalidad y sólo en algunas tareas operativas, debido a que son los elementos más visuales y, en consecuencia, se refuerza el estereotipo del bibliotecario. La literatura, en este sentido, ha generalizado al personaje en cuestión relacionándolo con mujeres maduras, robustas, con vestimenta conservadora, usa anteojos, peinada con "chongo" y con rasgos de personalidad introvertida, pasiva, tímida o extremadamente severa y hasta grosera.

Después de identificar la apariencia física y los rasgos psicológicos que conforman al estereotipo del bibliotecario, se analiza a este personaje en el cine mediante el discurso cinematográfico, el cual descifra la trama y el argumento. Éste último se refiere a la descripción de todo lo que se presenta en el lenguaje audiovisual, agrupado tanto en significantes visuales -que son imágenes en movimiento y signos escritos-, como en significantes sonoros -que son las voces, los ruidos y la música- (Cassetti, 1991: 171).

La metodología de lectura del discurso cinematográfico basado en representaciones sociales se utilizó para analizar las características físicas y psicológicas del personaje del bibliotecario, se describe el filme para contextualizarlo y después se descompone al fragmentarlo en secuencias para describir las escenas en las que aparece el bibliotecario, el ambiente donde se lleva a cabo la acción y los diálogos. Acto seguido se elabora un mapa con los elementos simbólicos de la narración que enumera los atributos del personaje del bibliotecario en las dimensiones física (apariencia y vestimenta) y psicológica (personalidad y emociones). Posteriormente, se reagrupan los elementos que caracterizan al o a los personajes del bibliotecario de los filmes seleccionados para estudiar las diferencias y semejanzas. Finalmente, se recompone el filme para analizar la caracterización física del personaje y de sus rasgos de personalidad (Iturbe, 2013: 40-81).

Las películas y los personajes analizados fueron: El ojo del huracán de 1956 (Alicia Hull y Martha Lockridge), Cosas de Mujeres de 1957 (Bunny Watson, Sylvia, Ruth y Peg), Eres un chico grande de 1966 (Bernard y Sr. Chanticleer), El nombre de la Rosa de 1986 (Jorge de Burgos), Se busca ama de casa de 1992 
(Betty Lou Perkins y Sra. Armstrong), Una chica divertida de 1995 (Mary y Judy), El bibliotecario: en busca de la lanza perdida de 2004 (Flynn Carsen).

Los resultados obtenidos del análisis estructurado nos permitieron identificar características distintas del bibliotecario a lo establecido en el estereotipo. Anteriormente se mencionó que la literatura ha asociado al bibliotecario principalmente con mujeres maduras, robustas, con vestimenta conservadora, que usa anteojos, peinada con "chongo" y con rasgos de personalidad introvertida, pasiva, tímida o, extremadamente severa, sin embargo, en los filmes analizados aparecen bibliotecarios hombres y mujeres, cuyas edades están en todos los rangos de edad (18-25 años, de 26-34, de 35-44, de 45 a 55 y de 55 a 65 años) Algunos son de complexión delgada o robusta, y su estatura puede ser alta o mediana. La vestimenta de los personajes está acorde al contexto y la moda de cada época, y va desde el estilo creativo o natural que proyecta una apariencia original y tiene como función la decoración y expresa individualidad (las encontramos en los personajes de Mary, Flynn); el estilo romántico, que proyecta calidez y gentileza y tiene como función expresar modernidad, aceptación o adaptación a los cambios de las cuatro jóvenes y atractivas referencistas (es el caso de Bunny, Peg, Sylvia, Ruthie); el estilo tradicional, que proyecta una apariencia conservadora, seria y sobria y tiene como función demostrar simbólicamente la pertenencia a un grupo ( como se ve en Judy, Martha, Betty Lou, Margaret Armstrong); el estilo elegante, que proyecta una apariencia formal, refinada o distinguida, y permite el reconocimiento de nivel social o estilo de vida (Alicia Hull, Sr. Chanticleer). Sobre los lentes, símbolo distintivo de la apariencia del bibliotecario, la mayor parte de los personajes analizados los portaban, sin embargo, se considera que su función es proteger los ojos del brillo y la luz, mejorar la visión o corregir problemas visuales, pero también se asocian a las personas que leen mucho. En la caracterización de personajes su uso está asociado a personas inteligentes, estudiosas, que por lo general leen constantemente, como adultos mayores y a ciertos grupos como profesores, y bibliotecarios.

Con respecto a las características psicológicas del bibliotecario, la revisión bibliográfica proyecta sus atributos como personas solitarias, retraídas o distantes, aisladas y tímidas; en suma, características negativas. Sobre los rasgos de personalidad de los bibliotecarios analizados, los atributos positivos identificados son los siguientes: en cuanto a interacción social, la caracterización del bibliotecario(a) se proyecta extrovertido, sociable, activo (Bunny, Ruth, Mary); en lo emocional, seguros y amables (Alicia y Judy); y en lo que se refiere a responsabilidad son organizados, responsables, ordenados y cuidadosos (Alicia, Bunny, Judy, Peg, Ruthie, Sylvia, Mr. Chanticleer).

En cuanto a los elementos que son diferentes, por ejemplo, en el filme $\mathrm{El}$ Nombre de la Rosa, Jorge de Burgos se proyecta retraído y solitario, no sólo porque es bibliotecario, sino porque es monje de una abadía. Asimismo, en $\mathrm{Se}$ busca ama de casa, la Sra. Armstrong es negativa y controladora, particularmente 
cuando prohíbe la hora del cuento, abogando por el silencio y control absoluto de la biblioteca, sin embargo Bettty Lou es lo opuesto a su jefa. Aun cuando los rasgos de personalidad de los bibliotecarios analizados no están enmarcados en el estereotipo, hay secuencias donde se proyectan estas características: -introvertidas, inseguras y tímidas-, como es la caracterización de Bernard, Betty Lou o Flynn.

Durante años, las particularidades físicas negativas y el comportamiento "dañino" del bibliotecario han conformado el estereotipo del que hablamos, debido a que únicamente se observan estos elementos, en términos descriptivos. De manera que la lectura e interpretación del contexto del personaje y los rasgos de personalidad son factores que derivarían en un cambio en la imagen y, por ende, en el estereotipo.

\section{LOS ROLES CULTURALES Y SOCIALES DE LOS BIBLIOTECARIOS EN CIEN AÑOS DE CINE}

La presencia de los bibliotecarios en las películas despierta interés por conocer las razones que conducen a los directores, productores o guionistas a elegirlos, ya sea como los personajes principales o como secundarios. Entre las razones de la elección de bibliotecarios y bibliotecas, planteamos que su representación social se encuentra relacionada con los atributos simbólicos del libro, éste a su vez tiene estrechos vínculos con la escritura a la cual se consideraba desde la antigüedad un poderoso agente de ideas y saberes, con capacidad de modelar las mentes y las conductas de los humanos. Posteriormente se extendió y fortaleció la representación de libros como un medio para alcanzar la sabiduría y, a partir del siglo XIX se fortaleció su uso en el proceso educativo de las sociedades. En la actualidad el libro goza de una imagen simbólica positiva, arraigada al saber, a la cultura y como un entretenimiento provechoso. De tal manera que sus cualidades se extienden al recinto que los resguarda y a las personas que lo atiende, es decir, los bibliotecarios. Por ello, se les puede considerar lugares y personas de una alta calidad moral, decencia, además de poseer una amplia sabiduría.

Las personas relacionadas con libros en general y en particular, como los bibliotecarios, los lectores y los escritores, están asociadas a comportamientos que tienden más a la introspección, la introversión, la seriedad, las actitudes hoscas y poco pacientes, también se suele pensar que tiene amplios conocimientos, son estudiosos y por ello requieren espacios de silencio y tranquilidad. En algunos casos las bibliotecas y los bibliotecarios son admirados y respetados, pero en otros pueden considerarse como aburridos, complicados, nada divertidos, ni atractivos. Dichos atributos o defectos son enfatizados por la cinematografía para utilizarlos como elementos simbólicos.

Al respecto, nos dicen R. Tevis y B. Tevis (op. cit.: 9) que durante el cine silente esas imágenes eran más producto de la idealización de directores, 
guionistas y actores. Pero a partir de los años treinta empezaron a representar a los bibliotecarios de carne y hueso - que habían percibido seguramente al frecuentar las bibliotecas y que se plasmaron en sus representaciones-, de manera que al llevarlos al cine se enfatizaron ciertos estereotipos personales al presentarlos realizando las actividades bibliotecarias, con ello se logró que se les imitara o que se exageraran determinados casos y actitudes. Es entonces cuando aparecen sellando libros, buscándolos o intercalándolos en las estanterías, llevando carritos con libros, atendiendo el servicio de préstamo, localizando alguna información; también aparecen letreros de silencio, lectores leyendo en las mesas o buscando libros en las colecciones bien organizadas. En las bibliotecas se aprecia orden y tranquilidad, en donde casi no se habla o se hace en voz muy baja. Por su parte, A. M. Chaintreau y R. Lemaitre (1993) también coinciden en su análisis sobre la imagen de los bibliotecarios, en los que están presentes los elementos antes descritos, tanto en la literatura como en el cine francés. Asimismo, los encontramos en la filmografía inglesa y oriental, es decir, se puede afirmar que los estereotipos y roles sociales son universales.

De tal manera, los elementos percibidos y reconocidos que caracterizan a los bibliotecarios tienen un arraigo simbólico y su imagen contiene suficiente información, por lo que resultan adecuados para representar determinados temas en el argumento fílmico, pues como señala Gubern: "la comunicación visual, con su atención y percepción muy selectivas, es más rápida, compleja y sutil que el lenguaje hablado, el sentido de la vista orientado a la percepción del mundo visible, posee capacidad de abstracción y generalización en la trama de la escena"(op. cit.: 15-16).

\subsection{LAS BIBLIOTECARIAS EN TEMAS DE GÉNERO}

Los temas feministas surgen en las primeras décadas del siglo pasado, en Estados Unidos, uno de ellos es la desigualdad de los salarios que recibían las mujeres en comparación con los de los hombres. A mediados del siglo XIX las mujeres empiezan a incorporarse en el mercado laboral con ingresos precarios. Entre esos espacios se encuentran las bibliotecas, pues no había muchos lugares decentes en donde ellas tuvieran espacios donde ingresar sin estudios, y la ventaja para esas instituciones era que podían pagarles un menor salario. Además el número de bibliotecas públicas, así como también en las instituciones educativas, empezaron a incrementarse de manera importante, en especial en Inglaterra y los Estados Unidos. En medio de esa situación, hacia la segunda década de los años $\mathrm{XX}$, las mujeres comienzan a hacer evidente su situación de desigualdad laboral y la falta de oportunidades para progresar, puesto que su único camino era el matrimonio con un hombre que tuviera una buena posición social. El tema empieza a abordarse en el naciente cine, el cual como espectáculo se arraigaba rápidamente entre la población y tenía un impacto social especial. 
La primera película silente de la que se tiene noticia en la que aparece una bibliotecaria es The librarian, (Reel Librarian, pag Web) de 1912, producida por la compañía norteamericana Edison Company, no es factible conseguirla, pero está mencionada en la filmografía de la actriz Mary Fuller, quien actúa en el papel de la bibliotecaria Betty Gibbs, por la imagen que se tiene de ella y siguiendo el análisis de la magnífica investigación de R. Tevis y B. Tevis, (op. cit: 9), identificaron que en el mayor número películas en la época del cine silente, los argumentos abordaban, entre otros problemas sociales, el de la desigualdad femenina en el ámbito laboral. Y en 1917 la película $A$ wife on the trial, otra bibliotecaria llamada Phyllis Narcissa Braithwait protagonizada por la joven y bella actriz de 25 años, Mignon Ander, se basó en la novela best seller: The rose garden husband de 1915, de la escritora Margaret Widdemar. La película tiene la singularidad de que fue dirigida y producida por una mujer, la escritora Ruth Ann Baldwin. La bibliotecaria Phyllis, de extracción humilde, es responsable de la sección infantil y hace pasar momentos dichosos a sus pequeños usuarios. Ella trabaja intensamente, incluso los fines de semana, recibe un salario 50.00 Dls. al mes. Su sueño es tener un jardín de rosas, y mediante un contrato acepta casarse y cuidar a un hombre joven, rico y bien parecido, pero inválido, lo hace para escapar del acoso de un pretendiente borracho y ordinario, ella lo atiende de manera solícita, como solía hacerlo con sus usuarios. Otra película es The Blot (1921), escrita, producida y dirigida también por una mujer, Lois Weber. El rol de la bibliotecaria Amelia es utilizado para demostrar el drama que viven las familias pobres que desempeñan trabajos dignos; al igual que ella, su padre es un profesor, ambos reciben salarios muy bajos, tienen deudas e incluso dificultades para comprar comida, asunto que hace pasar vergüenzas a la bibliotecaria quien prefiere no comer a aceptar alimentos robados. Amelia demuestra sus valores morales cuando descubre que un admirador rico que se hace pasar por un lector ávido, en realidad no lee y él confiesa que va a la biblioteca sólo por ella, pero no accede a casarse hasta después que él logra conquistar su corazón.

\subsection{LA EMANCIPACIÓN, LA EDAD Y EL ESTADO CIVIL DE LAS BIBLIOTECARIAS}

Las bibliotecarias también protagonizan a mujeres que buscan emanciparse, por lo general de edad madura, solteras o viudas; y además, aparecen en temas controvertidos, como las madres solteras o las que están encarceladas. Tal es el caso de la bibliotecaria Lul protagonizada por Barbara Stanwyck en la película Forbidden de 1932. Ella intenta emanciparse de una vida sin alicientes, se va de paseo a una isla del Caribe, decide tener una aventura y queda embarazada, tiene una hija de un político famoso casado, pero deja de verlo y un periodista la descubre, Lul lo asesina para proteger el honor del político y va a dar a la cárcel. 
Asimismo podemos encontrar en la cinematografía a las bibliotecarias viudas, quienes después de morir su pareja buscan empleo para tener un ingreso y lograr una forma de realización en un trabajo respetable. Varias de las películas que abordan estos temas dan cuenta de sus dificultades para labrarse una trayectoria después de cierta edad o de emanciparse de situaciones que culturalmente las limitan. En la película Only 38 filmada en 1923, una viuda ingresa a una biblioteca académica para tener ingresos y una vida propia, se enamora de un profesor, pero sus hijos gemelos la consideran vieja a los 38 años para emprender una nueva vida y rechazan la actitud tan independiente de la madre. Por su parte, en Salmonberries (1991), la bibliotecaria alemana Rosewitha en el momento de escapar de la Alemania Oriental, queda viuda al ser asesinado su esposo cuando intentan cruzar el muro de Berlín, ella escapa y desde entonces vive sola, de manera discreta y dedicada a su trabajo en una biblioteca pública de Alaska. Y la película más reciente de 2013, The Librarian, la bibliotecaria Carol Dearden protagonizada por Marcia Gay Harden, a los 40 años y siendo soltera, se siente frustrada y sola debido a que se dedicó sólo a su trabajo, decide transformar su vida y viaja a Costa Rica en busca de experiencias y tiene una aventura con un filósofo más joven que ella.

\subsection{LOS BIBLIOTECARIOS REPRESENTANTES DE VALORES Y VIRTUDES SOCIALES}

Otro de los temas que el cine aborda a manera de comedia son los valores, las virtudes y las dificultades que deben enfrentar las personas para mantenerse con actitud recta. En la cinta $A$ very good young man (1919), el joven y bien parecido actor Bryant Washburn representa al bueno y recto bibliotecario Le Roy Silvester, quien despierta dudas a su futura suegra por su buen comportamiento, por lo que es sometido a diferentes experiencias por su prometida para probar sus virtudes, de las cuales salió bien librado y nada logró corromperlo. A las cualidades de bondad, honestidad e ingenuidad se fueron incorporando el conocimiento, el gusto por el estudio y la lectura. El mismo caso es el de la trilogía El Bibliotecario que ya se mencionó anteriormente, quien tiene varias maestrías y doctorados; gracias a sus amplios conocimientos triunfa en las difíciles y peligrosa encomiendas que le solicita su jefe. En la película The black gold (2011) traducida como El Príncipe del desierto, Auda, un príncipe árabe, es un ávido lector que se encarga de una biblioteca, pero por varias razones debe salir a luchar y gracias a sus conocimientos diseña estrategias y logra ganar una batalla. En ambas películas los actores son galanes jóvenes que llevan a cabo los actos heroicos. Es de destacar que en el estereotipo del bibliotecario masculino una de las características es su sabiduría y su elevada afición por la lectura.

En cambio las bibliotecarias identificamos la bondad, solidaridad, amabilidad, o bien ayudan a sus usuarios en no sólo a encontrar libros, sino también a resolver 
otros problemas, como el conseguir un comprobante de dirección para obtener la credencial de la biblioteca, a estudiar para obtener un ascenso en su puesto, a encontrar libros y hasta salvar sus vidas, como son los casos de las que aparecen en las películas El agente de la estación, Hombres de honor, Todos los hombres de la reina, Mis tardes con Margaritte, Matilda, entre otras. La ya mencionada bibliotecaria Alicia Hull del Ojo del Huracán, se erigió en la defensa de la libertad de las personas a leer lo que quieran e informarse, también le daba su apoyo, orientación y confianza a uno de los niños que era asiduo a la biblioteca, lo escuchaba con paciencia, le prestaba libros, incluso alguno con ciertas restricciones. También promovió con fuerza la creación de una sala infantil.

Los bibliotecarios, considerados personas expertas en la recuperación de información, s muestran su inclinación a responder la necesidades de los usuarios, como se aprecian en la citada película Cosas de mujeres (Desk Set) Las bibliotecarias son eficientes, logran dar respuesta a todas las consultas de los usuarios. Ante la llegada de la enorme computadora la jefa y líder del personal, asume una actitud profesional demostrando que son de mente abierta y progresista; también hacen valer la importancia del trabajo de la sistematización de la información que llevan realizando por años, y de igual manera ponen de manifiesto que sus conocimientos no pueden ser superados ni por personas ajenas a la profesión ni por la máquina, y más bien demuestran que se requiere un trabajo de colaboración y que la máquina es una herramienta que no puede sustituir a las capacidades humanas.

Otro aspecto positivo que se rescata de la profesión bibliotecaria para transformar la vida de las personas, lo encontramos en Mary, Una chica divertida (Party Girl), una joven estrafalaria, con vida superficial, e incluso delictiva, pero el trabajo en la biblioteca le hace cambiar el sentido de su vida, allí descubre el gusto por la clasificación y el servicio a usuarios, también se inicia en la lectura. Después de cometer una falta a la normas de la biblioteca es despedida, entonces descubre su verdadera vocación y decide estudiar bibliotecología. La transformación de su personalidad se hace evidente en una actitudes responsables, respetuosa, solidaridad y apoyo con los usuarios, de paso, también en su apariencia física cambia, al usar lentes y traje sastre color gris.

\subsection{MUJERES SEDUCTORAS QUE ATRAEN LECTORES}

En algunas películas producidas entre el cine silente y el triunfo del sonoro, en plena depresión económica norteamericana y en un mundo en guerra, aparecen en el cine películas orientadas a divertir a la población, mediante el género comedia, en donde aparecen bibliotecarias muy atractivas con peinado y vestuario modernos, de acuerdo a la moda, presentan una actitud y comportamiento más sofisticados, dando una idea de liberación, sin embargo, son mujeres recatadas. Por lo general están protagonizadas por actrices bellas y famosas que a diferencia 
de las películas de los años veinte no esconden sus atractivos: Pola Negri protagoniza a la bibliotecaria Lily en Lily of the dust de 1920; en No Man of Her Own de 1932 el actor Clark Gable conquista a la irresistible bibliotecaria Connie Randall, interpretada por Carole Lombard; en Wonder man de 1945 aparece la guapa Virginia Mayo, quien hace el papel de la bibliotecaria Ellen Shanley; The music man de 1962, basada en una comedia musical de 1957, la bella bibliotecaria Marian Paroo es la actriz Shirley Jones. La característica de estas películas es que son comedias, en las cuales los hombres hacen todo lo posible para conquistar a las bibliotecarias, pero ellas por lo general se resisten a los cortejos y ponen al reguardo su honorabilidad.

\subsection{LOS BIBLIOTECARIOS EN HUMOR Y DRAMA}

Tímidos e inseguros con el sexo opuesto, son características de los hombres bibliotecarios que aparecen en temas de humor, combinado en ocasiones con drama: en Only two can play o Juego para dos (1962) Peter Sellers es un bibliotecario tímido que es seducido por una mujer casada con el pretexto de ayudarlo en mejorar su puesto. En la película You are a big boy now o Ya eres un gran chico (1966) una moderna y liberal usuaria toma la iniciativa para conquistar a un joven y tímido bibliotecario, a quien su mamá sobreprotege, destacando la liberación femenina. En las películas orientales $Y$ u Zhou Yu's train o El Tren de Zhou (2002) y Life in the universo o Más allá del universo (2003) también los bibliotecarios son tímidos y las mujeres tienen más iniciativa para desarrollar escenas jocosas, al final ellos prefiere preservan sus ideales de libertad e independencia.

\section{CONCLUSIÓN}

El material fílmico ofrece un rico material para analizar los estereotipos cinematográficos que caracterizan a los bibliotecarios, algunos, pese a que pueden considerarse negativos, sin embargo en el cine encontramos que son usados en roles que representan valores sociales y culturales, dado que resultan suficientemente creíbles, ya que coinciden con el imaginario social. Desde luego el tema de los bibliotecarios en el cine abre un campo de estudio que puede ayudar a explorar y contrastar la imagen que hoy en día los bibliotecarios tienen en la sociedad, lo que ayudaría al estudio de la representación de nuestra profesión y de la biblioteca. Asimismo su análisis permitiría identificar y explicar los elementos que se encuentran en el núcleo de las representaciones en las que se han encalado los estereotipos y que pueden tener efectos adversos, cuando se pretende despertar vocaciones y promover el ingreso al estudio de la bibliotecología. Sin embargo, al mismo tiempo encontramos elementos que refieren a las virtudes 
humanas presentes en el discurso cinematográfico, lo cual nos abre posibilidades de estudio sobre la responsabilidad social de los bibliotecólogos.

\section{REFERENCIAS BIBLIOGRÁFICAS}

BARTHES, Roland (1986). Lo obvio y lo obtuso. Imágenes, gestos y voces. Barcelona: Paidós Ibérica.

CASETTI, Francesco y CHIO, Federico Di (1991). Cómo analizar un film. Barcelona: Paidós.

DUPRÉ, Deirdre (2001). "The Perception of Image and Status in the Library Profession", en New Breed Librarian, vol.1, no.4, pp. 2-9.

ENGLE, Michael (1991). "The Librarian and the Crone: Myth and Reality?", en Special Library Journal, vol.37, no.1, p. 44.

ESPINOSA, Juan Carlos et al. (2009). "Personalidad y afrontamiento en estudiantes universitarios", en Universitas Psychologica, vol.8, no.2, pp. 311-322.

GARCÍA NIUBÓ, David (1999). "Reflexiones en torno a un profesional sin nombre", en Ciencias de la Información, vol.30, no.1, pp. 8-20.

GUBERN, Román. (2004). Patologías de la imagen. Barcelona: Anagrama.

INTERNET MOVIE DATABASE (2013). "The Librarian".

$<$ http://www.imdb.com/title/tt0489183> [Consulta: 23/03/2013]

ITURBE FUENTES, Luis Raúl (2013). "Las representaciones del bibliotecario en el discurso cinematográfico". Dirección: Elsa Margarita Ramírez Leyva. Tesis de Maestría. Universidad Nacional Autónoma de México, Posgrado de Bibliotecología y Estudios de la información.

JODELET, Denis (1984). "Representación social: fenómenos, concepto y teoría", en: Psicología social Pensamiento y vida social. Psicología social y problemas sociales. Buenos Aires: Paidós.

KNEALE, Ruth (2009). "Stereotypes? What stereotypes?", en: You don't look like a librarian: shattering stereotypes and creating positive new images in the Internet age. Medford: N.J., Information Today, Incorporated.

LEMAÎTRE, Renée; CHAINTREAU, Anne-Marie (1993). Drôles de bibliothèques le thème de la bibliothèque dans la littérature et le cinema. Paris: Cercle de la librairie.

MIRANDA LÓPEZ, Raúl "Cronología del cine mexicano 1896-1930. Cronos en el ojo". <http://es.scribd.com/doc/177674197/77580922-Cine-MudoMexicano> [Consulta: 23/03/2013]

PAZ YANES, Claudia (2002). "Bibliotecas de cine: una revisión de la imagen de las bibliotecas y los bibliotecarios en el séptimo arte (tópicos y estereotipos)", en Scire, vol. 8, no.2, pp. 117-140.

PINTO MOLINA, María; ACAL DÍAZ, Inmaculada (2008). "La biblioteca en el cine europeo: 
cine europeo: el caso de El nombre de la rosa", en Pliegos de Yuste: revista de cultura y pensamiento europeo, vol.1, no.7-8, pp. 123-134.

RADFORD, Marie (2003). "Librarians and party girls: cultural studies and the meaning of the librarian", en Library Quarterly, vol.73, no.1, pp.54-69.

RAMÍREZ, Elsa, et al. (2007). "Los bibliotecarios ¿Qué imagen proyectan en el cine?", en Hemera, vol.5, no.10, pp. 6-20.

RAMÍREZ, Elsa; ITURBE, Luis (2011). "La importancia social de la biblioteca y de los bibliotecarios: una muestra cinematográfica", en El bibliotecario, vol.10, no.82, pp. 21-27.

RUDOLPH, Megan Anne (2008). "Librarians in film: A changing stereotype", en A Master's Paper for the M.S. in L.S. degree, pp. 1-38.

SNOEK-BROWN, Jennifer (2013). "Reel Librarian". $<$ http://reel-librarians.com/2012/09/14/librarians-lost/> [Consulta: 30/03/2013]

TEVIS, Ray; TEVIS, Brenda (2005). The Image of Librarians in Cinema, 19171999. Estados Unidos: Jefferson, North Caroline, Inc.

WALKER, Stephen. (1993). "The librarian stereotype and the movies", en The Journal of Academic Media Librarianship, vol. 1, no. 1, pp.16-28.

\section{ANEXO 1. FILMOGRAFÍA}

1. ¡Eres un gran chico! [película]. Dirigida por Francis Ford COPPOLA, producida por Phil FELDMAN. Estados Unidos: Seven Arts Productions, 1966.

2. A very good young man [película silente]. Dirigida por Donald CRISP. Estados Unidos: Famous Players-Lansky Corporation, 1919.

3. A wife on trial [película silente]. Dirigida por Ruth Ann ALDWIN. Estados Unidos: Universal Film Manufacturing Company, 1917.

4. Cosas de mujeres [película]. Dirigida por Walter LANG, producida por Henry EPHRON. Estados Unidos: Twentieth Century Fox Film Corporation, 1957.

5. El agente de la estación [película]. Dirigida por Thomas MCCARTHY, producida por Robert MAY y Mary Jane SKALSKI. Estados Unidos: SenArt Films, Next Wednesday Productions, 2003.

6. El bibliotecario: en busca de la lanza perdida [película]. Dirigida por Peter WINTHER, producida por Sven CLEMENT y Dean DEVLIN. Estados Unidos: Turner Network Television, 2004.

7. El nombre de la rosa [película]. Dirigida por Jean-Jacques ANNAUD, producida por Bernd EICHINGER. Alemania occidental, Francia: Neue Constantin Film, Cristaldifilm, 1986.

8. El ojo del huracán [película]. Escrita y dirigida por Daniel TARADASH, producida por Julian BLAUSTEIN. Estados Unidos: Julian Blaustein Productions, 1956. 
9. El príncipe del desierto [película]. Dirigida por Jean-Jacques ANNAUD, producida por Tarak Ben AMMAR. Francia, Italia: Quinta Communications, 2011.

10. El tren de Zhou [película]. Dirigida por Zhou SUN, producida por Jianxin HUANG y William Kong. China, Hong Kong: China Film Co-Production Corporation. China Film Group, 2002.

11. El último día en el universo [película]. Dirigida por Pen-Ek RATANARUANG, producida por Wouter BARENDRECHT. Tailandia, Japón: Bohemian Films, Cinemasia, 2003.

12. Forbidden [película]. Dirigida por Frank CAPRA, producida por Harry COHN. Estados Unidos: Columbia Pictures Coporation. 1932.

13. Hombres de honor [película]. Dirigida por George TILLMAN, producida por Bill BADALATO. Estados Unidos: Fox 2000 Pictures, 2000.

14. Juego de amor entre dos [película]. Dirigida y producida por Sidney GILLIAT. Reino Unidos: Vale Film Productions, British Lion Film Corporation, 1962.

15. Lilly of the dust [película silente]. Dirigida por Dimitri BUCHOWETZKI. Estados Unidos: Famous Players-Lansky Corporation, 1924.

16. Matilda [película]. Dirigida y producida por Danny DEVITO. Estados Unidos: Tristar Pictures, 1996.

17. Mis tardes con Margaritte [película]. Dirigida por Jean BECKER, producida por Louise BECKER. Francia: ICE3, 2010.

18. No Man of Her Own [película]. Dirigida por Wesley RUGGLES. Estados Unidos: Paramount Pictures, 1932.

19. Only 38 [película silente]. Dirigida por William MILLE. Estados Unidos: Famous Players-Lansky Corporation, 1923.

20. Salmonberries [película]. Dirigida por Percy ADLON, producida por Eleonore ADLON. Alemania: Pelemele Film, 1991.

21. Se busca ama de casa [película]. Dirigida por Allan MOYLE, producida por Sarah BOWMAN. Estados Unidos: In the Bag Productions, 1992.

22. The blot [película silente]. Dirigida y producida por Lois WEBER. Estados Unidos: Lois Weber Productions, 1921.

23. The librarian [cortometraje silente]. Producida por Edison Company. Estados Unidos: Edison Company, 1912.

24. The librarian [película]. Dirigida por Juan FELDMAN, producida por Christian CALDERON. Estados Unidos: Mano a Mano Films, 2014.

25. The music man [película]. Dirigida y producida por Morton DACOSTA. Estados Unidos: Warner Bros, 1962.

26. Todos los hombres de la reina [película]. Dirigida por Stefan RUZOWITZKY, producida por Zachary FEUER. Alemania: Atlantic Streamline, 2001. 
Luis Iturbe Fuentes, Elsa M. Ramírez Leyva $\quad$ Estereotipos y roles sociales de los bibliotecarios...

27. Una chica divertida [película]. Dirigida por Daisy VON SCHERLER MAYER, producida por Harry BIRCKMAYER. Estados Unidos: Party Productions, 1995.

28. Wonder man [película]. Dirigida por Bruce HUMBERSTONE, producida por Samuel GOLDWYN. Estados Unidos: Samuel Goldwyn Studios, 1945. 